\title{
Introductory comment to Jay Greenberg's "Conversations with Oedipus"
}

\author{
Comentário introdutório ao artigo \\ "Conversando com Édipo", de Jay Greenberg
}

Sérgio Lewkowicz*

First of all, I would like to congratulate Dr. Flávio Kapczinski, Editor-in-Chief of Trends in Psychiatry and Psychotherapy, as well as the other members of the editorial board, for their initiative in opening this issue with an original paper on a psychoanalytic topic. Psychiatry has achieved great developments in different fields, e.g. psychopharmacology, different psychotherapeutic approaches, addiction treatment, and public mental health policies, among others. All these advances have consolidated psychiatry as a complex and multifactorial science. In this sense, bringing together all such different fields of interest is an important challenge in any psychiatric journal. We congratulate the editorial board for pursuing this goal.

"Conversations with Oedipus," by Jay Greenberg, included in the present issue, perfectly suits the purpose of describing the changes faced by psychoanalysis as it evolves. In the beginning of the paper, Greenberg engages the reader in an interdisciplinary framework, establishing dialogs with ancient Greeks, especially Sophocles and two plays on Oedipus: Oedipus Tyrannus and Oedipus at Colonus. From there on, he resorts to philosophers, historians, classicists and other professionals to show that we as psychoanalysts, in our daily practice, share the same worries faced by humanity, at least in the Western society, for thousands of years. Greenberg describes how Greek tragedies created narratives of emotions experienced by men, through myths, legends, and fantasies, with the aim of allowing a better understanding of and some degree of control over our anxieties in relation to the unknown and the strange.

With the invention of psychoanalysis, Freud tried to use the same narrate principle on an individual scale, namely, the principle of cure through story telling. However, Greenberg believes that psychoanalysis has retreated from this method, by starting to limit their focus to the patient's drives and wishes; according to

* Full member, Associação de Psiquiatria do Rio Grande do Sul (APRS) and Sociedade Psicanalítica de Porto Alegre (SPPA). Analista didata, SPPA. E-mail: serlew@ terra.com.br

No conflicts of interest declared concerning the publication of this editorial.

Suggested citation: Lewkowicz S. Introductory comment to Jay Greenberg's "Conversations with Oedipus". Trends Psychiatry Psychother. 2012;34(2):49-50. 
this perspective, man would be governed by drives and wishes, and the "know yourself" motto would be enough to bring about cure. The context, the participation of others, of the so-called objects, was not valued in early psychoanalysis and ended up losing strength - differently from the story of Oedipus, who survived an attempted murder after being abandoned by his biological parents and was subsequently deceived by his adoptive parents. The story of Oedipus, or the context described, came up as tentative explanation, an attempt to make sense of the terrible crimes that Oedipus was about to commit.
Fortunately, contemporary psychoanalysis shows a higher balance between the intrapsychic (or drives) and the intersubjective (what comes from the outside world).

In the clinical vignette described by Greenberg, we see an active, humane, engaged analyst, one who respects the time and limits necessary for his patient to change.

"Conversations with Oedipus" is a paper that thoroughly illustrates the complexity of contemporary analytical method. We are definitely proud and privileged to have his original paper published in our journal. 